\title{
ALGUNAS OBSERVACIONES SOBRE EL ESTADO ACTUAL DE LA BIOÉTICA EN ARGENTINA
}

\section{Delia Outomuro*}

Resumen: Este trabajo propone como tesis que la bioética en la Argentina corre el riesgo de operar como institución, en el sentido antropológico del término, y que, como tal, lejos de contribuir a la cristalización de la racionalidad emancipatoria, cumple la función de legitimar el statu quo. En la bioética argentina coexisten las etapas emotiva, reconstructiva y de consolidación disciplinaria, con todos los peligros inherentes a cada una de ellas. El legalismo y la juridización de los conflictos éticos, el fundamentalismo, el charlatanismo, la expertocracia y el snobismo desvirtúan su cometido de convivencia democrática.

Finalmente, se postula que la bioética debe promover la realización de la comunidad ideal de comunicación y que, por lo tanto, el carácter pluralista, transdisciplinario y procedimental debe prevalecer en este discurso como condición sine qua non para la articulación de los intereses emancipatorios de las personas.

Palabras clave: Bioética, peligros, institución, statu quo, pluralismo, emancipación

\section{SOME OBSERVATIONS ON THE CURRENT STATE OF BIOETHICS IN ARGENTINA}

\begin{abstract}
This paper proposes as thesis that in Argentina bioethics runs the risk of operating as an institution in the anthropological sense this term and that, as such, far from contributing to the crystallisation of the emancipatory rationality, it performs the function of legitimating the statu quo. In Argentina, the three bioethic stages (the emotive, the reconstructive and the consolidation stage) coexist, with all the inherent dangers to each one of them. The legalism and the lawfulness of the ethical conflicts, the fundamentalism, the cheaters, the expert-cracy and the snobbism adulterate its real purpose of democratic coexistence.

Finally, it is postulated that bioethics should promote the realisation of the ideal community of communication and that, therefore, the pluralistic, transdisciplinary and procedural character should prevail in this speech like a sine qua non condition for the articulation of people's emancipatory interests.
\end{abstract}

Key words: Bioethic, dangers, institution, statu quo, pluralism, emancipation

\section{ALGUMAS OBSERVAÇÕES SOBRE O ESTADO ATUAL DA BIOÉTICA NA ARGENTINA}

Resumo: Este trabalho apresenta a tese de que a bioética na Argentina corre o risco de funcionar como instituição, no sentido antropológico do termo, e como tal, longe de contribuir para a cristalização da racionalidade emancipadora, cumpre a função de legitimar o estatus quo. Na bioética Argentina coexistem as etapas emotivas, reconstrutiva e de consolidação disciplinar com todos os perigos inerentes à cada uma delas. O legalismo e o jurisdicismo dos conflitos éticos, o fundamentalismo, o charlatanismo, a espertocracia e o esnobismo desvirtuam a convivência democrática.

Finalmente, postula-se que a bioética deve promover a realização da comunidade ideal de comunicação e que, portanto, o caráter pluralista, transdisciplinar e prodecural deve prevalecer no discurso como condição sine Qua non para a articulação dos interesses emancipatórios das pessoas.

Palavras chave: Bioética, perigos, instituição, status quo, pluralismo, emancipação

Profesora Regular Adjunta de la Facultad de Medicina en la Universidad de Buenos Aires (UBA). Coordinadora de la Unidad Académica de Bioética en el Departamento de Humanidades Médicas de la misma Facultad.

Correspondencia: doutomuro@fmed.uba.ar 


\section{Introducción}

Poco tiempo ha transcurrido desde que Van Rensselaer Potter introdujera el neologismo "bioética" al titular su libro Bioethics: Bridge to the future, publicado en 1971. En estos algo más de treinta años, lo denotado por tal significante se ha impuesto como disciplina, es decir, en términos de Roland Barthes, como discurso enseñable. De hecho, existe una comunidad de hablantes que comparte (?) el lenguaje bioético, que constituye los objetos de estudio, que cree en ellos y que cuenta con seguidores y discípulos(1). Se trata de un discurso que es también un producto, en la medida en que, con él, se identifican comisiones nacionales, comités, cursos, centros de investigación y revistas(2-4). La máxima expresión como producto se evidencia en su principal textbook, me refiero al clásico libro Principles of Biomedical Ethics, que Beauchamp y Childress publicaran en 1979.

No obstante, si observamos detenidamente a la comunidad de hablantes que dice compartir el discurso bioético, podemos sorprendernos al ver que, en realidad, no todos hablan el mismo idioma ni comparten los mismos productos y, ni siquiera, se proponen los mismos objetivos. En lenguaje kuhniano, la bioética pareciera estar en un estadio pre-paradigmático.

El carácter polisémico del término bioética, manifestado a través de las múltiples definiciones que encontramos, no es un hecho menor. Esta multiplicidad de acepciones deja espacio para una vaguedad -e incluso, en algunos casos, ambigüedad- que permite la inclusión de actores, discursos y temáticas que, en mi opinión, conspiran contra el verdadero propósito de la bioética. La ética es parte inevitable de la bioética y la ética es, inevitablemente, filosofía. Y si algo hemos de pedir a la filosofía, es que contribuya a la racionalidad emancipatoria. Nada más lejos de la filosofía que mantener las cosas tal como están ${ }^{1}$.

Sócrates se llamaba a sí mismo “el tábano de Atenas” y no por nada fue condenado a beber cicuta.
Propongo como tesis que la bioética, fenómeno reciente de nuestra cultura occidental judeocristiana, corre el riesgo de operar como institución, en el sentido antropológico del término, y que, como tal, lejos de contribuir a la cristalización de la racionalidad emancipatoria, cumple la función de legitimar el statu quo.

Reconozco la audacia de esta afirmación y, por ello, limitaré el análisis al estado actual de la bioética en Argentina, aunque es posible que muchas de sus notas distintivas sean extensibles al resto de América Latina y, tal vez, a la bioética en general. No obstante, esta última afirmación requeriría una tarea de fundamentación que excede mi actual propósito.

Para llevar a cabo este objetivo comenzaré recordando el concepto antropológico de institución desde la perspectiva funcionalista y funcional-estructuralista. Luego iré mostrando algunas características que el discurso bioético ha adquirido en mi país y que, como dije, lo pueden hacer funcional a la estructura social vigente, desnaturalizando su verdadero cometido. Finalmente, intentaré mostrar que el carácter democrático, pluralista, transdisciplinario y procedimental debiera prevalecer en este discurso como condición sine qua non para la articulación de los intereses emancipatorios de las personas.

\section{Cultura e instituciones: su función}

El concepto de cultura ha variado a lo largo del tiempo. No se trata de un concepto estático sino de un constructo. Las ideas dominantes en cada momento lo condicionan y, de esta manera, iluministas, evolucionistas, funcionalistas y estructuralistas diferirán en su conceptualización. Me remitiré a Malinowski y a Radcliffe Brown quienes definen cultura como conjunto de instituciones.

Para Malinowski una institución es un grupo humano vinculado a un medio ambiente, dotado de equipamiento material y del conoci- 
miento para su uso, sumado a normas y leyes que gobiernan al grupo, más un conjunto de creencias y valores, tendiente a cumplir una función ${ }^{2}$. La función (y esto es muy importante) es satisfacer alguna necesidad psicobiológica del individuo. En otras palabras: dada una necesidad psicobiológica, allí estará la cultura para crear alguna institución que la satisfaga.

Por su parte, Radcliffe Brown, considera que la cultura y, por lo tanto las instituciones, no responden a las necesidades del sujeto sino que, por el contrario, satisfacen las necesidades de la sociedad. En este sentido, la institución subordina a cada individuo a las demandas sociales. La cultura, a través de las instituciones, impone pautas de conducta estandarizada con el fin de mantener el orden establecido. Por lo tanto, una institución es una forma de comportamiento estandarizado cuya función es resolver la tensión entre intereses, evitando una ruptura de las relaciones sociales que afectarían el funcionamiento de la estructura social; en tal sentido, la institución impone sanciones positivas (de aprobación) o negativas (de castigo) según se cumplan o no las normas(5). Las religiones y el poder judicial son ejemplos paradigmáticos.

\section{Observaciones sobre el estado actual de la bioética}

La bioética llega a la Argentina de la mano de José Alberto Mainetti. Con él, el discurso bioético transitará por el campo de las humani-

\footnotetext{
Tomemos como ejemplo a la medicina o su equivalente en otras culturas (magia, curanderismo, hechicería, etc.). Ella es una institución que satisface la necesidad de mantener o restaurar el estado de salud del individuo, independientemente de lo que cada cultura entienda por salud. La materialización de dicha institución también variará de cultura en cultura, pero siempre podrán identificarse los elementos contenidos en la definición. En la medicina occidental, el grupo humano está conformado por los profesionales de la salud; el medio ambiente será el hospital, el centro de salud o el consultorio; el conocimiento está representado por el saber contenido en las distintas teorías médicas; existen normas y leyes que reglamentan el ejercicio profesional y, finalmente, creencias y valores compartidos.
}

dades médicas y estará fuertemente impregnado, en mi opinión afortunadamente, de contenidos históricos y sobre todo antropológicos. A través de la Fundación Mainetti y del Departamento de Humanidades Médicas de la Universidad de La Plata irá, poco a poco, adquiriendo entidad y transitando por las tres etapas evolutivas que distingue Fernando Lolas: las etapas emotiva, reconstructiva y de consolidación disciplinaria(1) ${ }^{3}$. En las características que describiré a continuación pretendo mostrar que en la bioética argentina coexisten estas tres etapas y que los peligros inherentes a cada una de ellas desvirtúan su cometido emancipatorio.

\section{La confusión con el legalismo y la juridificación de los conflictos bioéticos}

El discurso ético distingue entre legalidad y legitimidad. Aquello que es conforme a la ley positiva es legal. Aquello que es conforme a la ética es legítimo. Como es de suyo conocido, no todas las leyes son éticas, es decir, no todas las leyes responden a una fundamentación ética que las legitime. A su vez, no todo lo que puede ser ético es legal. Lo ideal sería que existiera una coincidencia plena entre lo ético y la ley, pero no siempre es así. Las leyes son insuficientes para garantizar que una sociedad sea justa pues no siempre protegen eficazmente los derechos de los ciudadanos y, además, no suelen contemplar los casos particulares.

La bioética, en tanto transdisciplina, ha de dialogar con el derecho positivo, pero evitando

\footnotetext{
En la primera se moviliza fuertemente la opinión pública, todos son expertos porque todos tienen alguna sensibilidad frente a lo que pasa y todos opinan. En la segunda, los cultores de la nueva disciplina empiezan a ver sus conexiones históricas y sociales, existiendo aquí el peligro de asimilar lo nuevo a lo que ya se sabía. Finalmente, la tercera etapa de consolidación disciplinaria se caracteriza por la publicación de revistas especializadas, el otorgamiento de grados académicos, la fundación de sociedades, la creación de cofradías de expertos y la profesionalización. Esta etapa conlleva el riesgo de la mercantilización del saber bioético, de su conversión en un producto de mercado con la posibilidad de ser vendido, comprado o intercambiado.
} 
la tentación de reducirse a él y de incurrir en el legalismo. La reflexión ética no sólo excede el marco de lo legal sino que, además, lo incluye como objeto de estudio en su intento de legitimación del derecho.

Sin embargo, en nuestro medio es habitual la confusión de la ética y, por lo tanto, de la bioética con el derecho y la deontología médica. Es frecuente observar, verbigracia, el tratamiento de problemas tales como el aborto, el transplante de órganos o la problemática referida al SIDA ${ }^{4}$, exclusivamente desde la ley vigente. Junto al legalismo, se advierte una tendencia a juridificar la conflictividad bioética, en la convicción de que cada sentencia resuelve cada problema. Cabe señalar que "juridificar es un tipo de acción propio de sociedades con escasa libertad, mientras que en las sociedades más libres la necesidad de la regulación legal es menor porque los ciudadanos ya actúan correctamente(6)”.

Es notoria la insistencia de los legisladores en la presentación de proyectos de ley sobre clonación, investigación con seres humanos, salud reproductiva o la tan mentada "muerte digna”. Las propuestas se formulan con pasmosa superficialidad y sin que estos temas hayan sido siquiera motivo de un profundo y verdadero debate en la comunidad, como lo ha sido, por ejemplo, el tema de la eutanasia entre la población holandesa. Se respira un aire de ingenuo positivismo en estas pretensiones. Del mismo modo en que la filosofía decimonónica confiaba la resolución de los grandes problemas de la humanidad al desarrollo de la ciencia, nuestros legisladores (y no sólo ellos) apuestan a que la ley disuelva los dilemas bioéticos. Hecha la ley, resuelto el problema. Pero nada más lejos de la realidad.

4 En la Argentina existe la Ley Nacional de SIDA No 23.798/ 90 (Decreto reglamentario $N^{\circ} 1.244 / 91$ ). Si bien la misma pretende evitar la discriminación negativa así como respetar la autonomía, un análisis crítico de la misma pone de relieve algunas inconsistencias en relación con estos propósitos.
Además, como señala Adela Cortina, el Estado exige el cumplimiento de las normas jurídicas promulgadas mediante la coacción, es decir, posee el poder de castigar a quien las transgreda. De esta manera, el derecho tiende a preservar la racionalidad estratégica en lugar de la racionalidad comunicativa ${ }^{5}$ porque la ley suele cumplirse estratégicamente: por miedo a la sanción y no por propia convicción.

El legalismo y la juridificación de la bioética -en tanto imponen un modo de acción uniforme, en tanto no dejan espacio para la reflexión ni para el diálogo, en tanto impiden la realización de los diferentes proyectos de vida de los actores sociales- sólo contribuyen a dejar las cosas como están. La institución bioética, al igual que el apego farisaico a la ley, cumple así la función de mantener vigente el ethos hegemónico. El reduccionismo legal de los problemas éticos equivale a renunciar al análisis racional de los mismos y a no asumir la responsabilidad de las propias decisiones. El legalismo corresponde a la etapa infantil (Piaget) y convencional (Kohlberg) de la formación de la conciencia.

\section{El fundamentalismo como otra estrategia para perpetuar el statu quo.}

En la misma línea del legalismo, se advierte el peligro del fundamentalismo, sea este religioso o no. Para las ideologías antiliberales hay principios apodícticos y autoevidentes. Aquellos iluminados, que creen tener el privilegio de aprehenderlos, se endilgan el derecho y el deber de exigir su cumplimiento a todos,

\footnotetext{
K.O. Apel y J. Habermas distinguen entre racionalidad estratégica y comunicativa. Quien hace uso de la primera considera a los interlocutores como medios para sus propios fines; en este plano es factible la manipulación y la coacción. En cambio, una comunidad de diálogo que se maneje con la racionalidad comunicativa considerará a todos los interlocutores en simetría, con los mismos derechos de defender argumentativamente sus intereses y, finalmente, aceptará los proyectos compatibles con los intereses de todos, aunque difieran entre sí.
} 
incluso mediante la fuerza. En nuestro ámbito latino y católico algunos discursos totalitarios suelen estar ligados a cosmovisiones religiosas. Para muchos, la tolerancia es todavía un vicio y la intolerancia una virtud. "La bioética se está convirtiendo en nuestro medio en un lugar de confrontación de las actitudes liberales y antiliberales, o tolerantes e intolerantes. El pluralismo es visto en nuestro mundo latino, aún hoy, como un grave y serio peligro(7)”.

A diferencia de la secularidad presente en la bioética norteamericana, los discursos bioéticos latinoamericanos suelen estar sesgados por estas cosmovisiones religiosas, muchas veces de manera solapada o revestida de un maquillaje pseudopluralista. Al confundir ética con religión se corre el riego de adoptar posturas fundamentalistas. En estos casos, la sociedad deviene totalitaria, porque un grupo impone a los demás su ética de máximos y aquellos que no compartan ese ideal de felicidad impuesto se ven discriminados y/o coaccionados. Por desgracia, en la historia abundan los ejemplos que ilustran las graves consecuencias acarreadas por este tipo de actitudes.

Quien trabaje en ética seriamente ha de tener presente la diferencia entre ética y moral, así como ha de tener claro que no existe una única moral como tampoco una sola teoría ética. Deben ser reconocidas y respetadas las morales religiosas, pero también ha de rechazarse cualquier tipo de adoctrinamiento, pues ello atenta directamente contra la esencia de la bioética.

En este sentido es de destacar la posición de Tristram Engelhardt, quien confiesa ser "católico ortodoxo, tejano converso” y tener convicciones morales que difieren sustancialmente de su propuesta bioética. Su proyecto apuesta, sin embargo, a una sociedad libre y democrática y permite vincular a "extraños morales". Como estos extraños morales "no escuchan a Dios” de la misma manera, sólo resta la opción de un acuerdo pacífico entre ellos acerca de cómo encarar cada conflicto(8).

Cuando una comunidad identifica la moral con la religión, los no creyentes se encuentran en una situación compleja. El apelar a argumentos para defender sus valores y principios es visto con reticencia pues, para los creyentes, la fundamentación de la obligación moral se halla sólo en la voluntad de Dios.

Estas posturas son incongruentes con una bioética entendida como disciplina dialógica. En este marco, su discurso se legitima precisamente por ser un diálogo secular y procedimental. No hay aquí, por lo tanto, lugar para "el reduccionismo creencial de aquellos que intentan imponer sus convicciones a otros y creen su deber propagar dogmas. Es por eso incongruente ad initio una bioética dogmática, fundamentada en un esfuerzo misionero o en el magisterio confesional (3, pp. 29-39)”.

\section{El charlatanismo como expresión de la etapa emotiva de la bioética}

Como señalara, la etapa emotiva perdura en nuestra bioética y su mayor riesgo es el charlatanismo. En este tema no están ausentes los medios de comunicación. Lamentablemente, los medios no suelen aportar información, mucho menos conocimiento. Su propósito es comunicar la noticia; y noticia no es sólo lo nuevo o infrecuente sino lo que conmueve, aquello que provoca impacto social.

La presentación amarillista y, con inusitada frecuencia, de situaciones relacionadas con la eutanasia, el transplante de órganos, las técnicas de fertilización asistida y, más recientemente, con la clonación, provocan la curiosidad de la población e invitan a arduas polémicas en torno a los límites que ha de tener la ciencia.

Por cierto que ha de celebrarse la participa- 
ción de la comunidad en estos asuntos, como en cualquier otro tema de interés público. Es más, uno de los méritos de la bioética es haber acortado las distancias entre "expertos” y profanos. Pero a lo que me refiero es al curioso fenómeno sociológico por el cual algunas personas se arrogan el derecho de dictaminar acerca de lo que está bien o está mal, de lo que debe o no debe hacerse, sin haber hecho siquiera el mínimo esfuerzo intelectual por fundamentar sus afirmaciones. Muchas veces se trata de buenas personas o de personas con buenas intenciones. Pero la bondad y la sensatez no se implican mutuamente.

Quizás convenga aquí recordar la clásica distinción aristotélica entre doxa y episteme. La primera es la opinión, el pre-juicio. La segunda es el conocimiento, el juicio. Todos podemos opinar y todos también podemos formular juicios. El problema de los charlatanes consiste en que presumen de doctos y se mantienen en el campo de la doxa considerándola ortodoxia.

También aquí sería atinado distinguir entre el saber moral y el conocimiento ético. Moral y ética coinciden en el lenguaje normativo en que se expresan pero difieren en otros múltiples aspectos. La moral presupone principios y los aplica a casos concretos, responde a la pregunta qué debo hacer frente a esta o aquella situación. Es un saber espontáneo, pre-reflexivo, pre-sistemático y a-crítico. Se desenvuelve en el plano de lo que es de hecho, de facto. En cambio, a la ética le interesa saber de dónde extraen su validez las normas o costumbres, de dónde surge su obligatoriedad. En otras palabras, indaga por el por qué debo; pretende pasar de lo que es de facto a lo que es de jure, del plano del ser al plano del debe ser. La reflexión ética intenta fundamentar las normas, las costumbres, los valores; es la aplicación de la razón a ese conjunto de creencias, hábitos y có- digos de normas que cada cultura posee como una de sus características constitutivas(9).

Nuestros charlatanes se mueven en el plano de la doxa y de la moral. Pero el tratamiento serio de cualquier tema (incluso más allá de la bioética) supone la deliberación crítica. Esto significa reconocer que la razón tiene, por un lado, presupuestos y, por otro, la capacidad de reflexionar sobre ellos críticamente. Significa, asimismo, reconocer los límites de la racionalidad: el hecho de que la razón humana no puede dirimir definitivamente las distintas cuestiones. No sólo Dios, también la Razón ha muerto. Por eso, quien delibera críticamente sabe que no hallará un respuesta definitiva, pero también sabe que tiene que considerar distintas opciones y que no todas ellas están sustentadas por argumentos del mismo peso(7).

Resulta llamativo observar que en el charlatanismo (en ese manejo acrítico, asistemático y pre-reflexivo de los temas éticos) pueden distinguirse, al menos, dos grupos de individuos. Por un lado, encontramos a aquellos que, llegados a cierta edad deciden incursionar en este campo del mismo modo que lo harían en cualquier actividad lúdica o recreativa. Suelen ser profesionales de la salud que han gozado de éxito y prestigio en su profesión, por ejemplo eximios cirujanos o destacados jefes de servicio. Pasados los años de labor y encaramados aún en el reconocimiento obtenido en su vida académica, creen estar en condiciones de dictaminar, como lo hicieron quizás legítimamente en sus respectivas especialidades, sobre asuntos morales ${ }^{6}$. Por otro lado, hallamos a una serie de individuos que, en este caso,

\footnotetext{
6 Alguien ha dicho que la medicina ha salvado a la ética. Análogamente he escuchado decir a otros que la bioética ha salvado a la historia de la medicina. Hasta los ochenta, era frecuente en nuestro medio que los médicos, llegados a su edad jubilatoria, incursionaran en la historia de la medicina con la misma superficialidad y falta de rigor que hoy se observa en bioética. Los historiadores respiran ahora aliviados.
} 
no suelen proceder exclusivamente del campo de la medicina; se trata de personas simples, posiblemente bien intencionadas, pero cuyo afán de protagonismo llega a obnubilar de tal modo su autocrítica que son capaces de hablar de todo en cualquier lugar y ocasión.

La bioética viene a funcionar aquí como aquella institución que satisface las necesidades psicológicas de la meno/andropausia de los unos y de la megalomanía de los otros. El tema parece menor pero en realidad no lo es, porque también conlleva el peligro del autoritarismo. Autoritarismo que no siempre es fácil de identificar, pues suele estar encubierto por el velo de la seducción que estas buenas personas despliegan: "la ignorancia piadosa, cuando es militante y pontifica, hace un daño irreparable a la bioética(3, p. 69)”. Yo agregaría: y a la sociedad.

\section{La expertocracia exclusiva y excluyentes de los "bioéticos"}

Como ocurre con cualquier disciplina, la bioética -al entrar en la etapa de consolidacióncuenta con sus propios especialistas. Por cierto es éste un peligro incipiente en nuestro medio ya que lo que más abunda son los representantes del tópico anterior. Sin embargo, poco a poco se advierte esta tendencia hacia la expertocracia. Ello ocurre en la medida en que proliferan los posgrados en este campo, pues quienes egresan suelen confundir, a veces, el tipo de experticia que han adquirido.

Muchos egresados se ofrecen como asesores o consejeros bioéticos y el mercado suele ser, en ocasiones, propicio, pues es tal el desconocimiento sobre el tema que no pocas instituciones sanitarias aspiran a contratar a estos presuntos expertos con el propósito de hallar solución a todos sus problemas. Del consultor ético se espera pragmatismo, esa respuesta acertada que evite la incomodidad psicológica de la incertidumbre y, por qué no, los costos de la administración sanitaria y de los tribunales de justicia.

Se olvidan que, en bioética como en ética, más que problemas existen dilemas y más que resolución hay, con suerte, disolución de los mismos. Quienes demandan soluciones de expertos, en el fondo buscan una autoridad moral que les permita garantizar e imponer una determinada política sanitaria. No comprenden que ni Dios, ni la Razón ni la Bioética evitarán la perplejidad que se siente frente a cualquier conflicto moral, como así tampoco nos liberarán de estar condenados a la libertad.

Cuando esto ocurre, esto es, cuando el experto decide y dictamina, nuevamente la bioética se desvirtúa y funciona como institución que satisface, o bien la necesidad de protagonismo del experto o bien la necesidad de persistencia del sistema. La bioética acaba formando parte de lo establecido. Porque, como también sostiene Tristram Engelhardt “estas consultas y este asesoramiento pueden desembocar en la imposición de una visión moral, de una ideología u ortodoxia moral particular como si la razón misma lo exigiese. Tales asesores trabajan en parte como lo hacen sacerdotes, rabinos o pastores en un contexto religioso, pero sin admitir una actitud sectaria $(8, p .17)$ '. Y, en este sentido, el peligro que representa el experto es aún mayor al del charlatán o al del fundamentalista, pues bajo el prestigio cosmético de una formación académica (knowledge is power) pretende conocer e imponer una determinada moral secular material.

Como afirma Victoria Camps, el personaje denominado con el barbarismo "bioeticista" nunca se equivoca ni podría hacerlo porque, como de ética se trata, se supone que aquí no hay lugar para la mala praxis, como en las especialidades médicas. La verdad o la falsedad no pertenecen a la ética. Hago propias las siguientes expresiones: 
"Por mi parte, veo un peligro en la concepción de la ética que pretende equipararla a cualquier otra disciplina. El conocimiento moral no es exactamente un conocimiento más, sumable a los distintos saberes, cada vez más específicos y especializados. Ni el filósofo, el eticista o como quiera llamársele, tiene que convertirse en un experto entre otros, un experto que atiende a un aspecto del conocimiento que él domina porque ha hecho de él su profesión. El peligro es profesionalizar la bioética y crear al 'bioeticista'(10)".

Pero, entonces, ¿deberíamos continuar con la formación académica de posgrado?, ¿puede o no haber expertos o especialistas en bioética? Y si la respuesta es afirmativa, ¿a qué tipo de experticia y competencias se hace referencia?

Por mi parte considero que es deseable que continúe la formación en bioética, tanto en el posgrado como en el pregrado, en especial en las carreras vinculadas a la salud. Ahora bien, cuando hablamos de formación de posgrado en bioética debería quedar claro que el propósito no es formar especialistas o expertos que resuelvan los problemas morales. Creo haber argumentado lo suficiente a este respecto e insisto que en una sociedad libre, pluralista y democrática no hay lugar para la profesión de moralista. Por lo tanto, las competencias que ha de tener quien tome estos cursos se limitarán a un papel algo más modesto que el de dar respuestas categóricas. Su tarea será la de poner su formación humanística al servicio del análisis de los conflictos éticos, iluminándolos como tales, descubriendo los valores en juego y permitiendo la participación simétrica de todos los afectados en la toma de decisiones. La pericia (expertise) del mal llamado bioeticista será más un "saber cómo” que un "saber qué”. En síntesis, su experticia ha de ser procedimen- tal, es decir, la identificación del procedimiento justo para intentar resolver el problema.

Esperar otro tipo de competencias del egresado es sencillamente insensato porque el discurso bioético (se ha dicho hasta el cansancio) es un discurso sui generis; como señala Fernando Lolas: un saber de los intersticios que dejan entre sí diversas disciplinas, un discurso transdisciplinario. Nadie que no sea omnisciente puede arrogarse la propiedad de semejante empresa.

\section{El snobismo bioético (last but not least)}

He aquí una característica de reciente adquisición: la bioética se ha puesto de moda. No sólo todos quieren ser "bioéticos" sino que también todo, es decir, cualquier cosa deviene un fenómeno bioético. En este sentido, la vaguedad que caracteriza el término ha contribuido a evitar un atinado recorte de la realidad. Resulta llamativo, por ejemplo, que la corrupción presente en algunos sectores del gobierno o de la administración pública o privada sea considerada un problema bioético, incluso entre quienes dicen saber de la materia. Otro tanto ocurre con el bioterrorismo, las armas biológicas, las guerras en general, la participación de los profesionales de la salud en actos de tortura, los abusos sexuales o los debates feministas, por citar algunos ejemplos. No cabe duda de que en todas estas cuestiones exista un problema ético. Pero no todo problema ético es un problema bioético. No tener esto claro es nuevamente confundir los campos y reducir la ética, cuyo ámbito de reflexión es mucho más amplio, a una disciplina que tiene bastante de ética pero que no la incluye totalmente.

\section{Conclusiones}

Jürgen Habermas distingue tres racionalidades: técnica, hermenéutica y emancipatoria. Cada una se vincula con algún 
tipo de interés. La primera, con intereses técnicos y tiene como finalidad el dominio y control de la naturaleza. La segunda se relaciona con intereses comunicativos, su propósito es la comunicación y el entendimiento (aunque, a veces, la incomunicación y los malos entendidos) entre individuos y comunidades. La tercera tiene que ver con intereses que persiguen la emancipación, la liberación. Esta racionalidad es propia de la reflexión y de las disciplinas críticas.

En una comunidad ideal de diálogo, los hablantes no están condicionados más que por intereses emancipatorios, de modo tal que la autorreflexión permite establecer modos de comunicación haciendo razonables las interpretaciones(11). En este contexto, el mejor argumento es aquél que nadie impone, pero que se impone a todos. La bioética debería promover la realización de esta comunidad ideal de comunicación. De todas las definiciones de bioética, y en el marco teórico de la ética discursiva, rescato la siguiente como el medio más adecuado para alcanzar ese objetivo:

“Como bioética en este carácter (procedimental y metodológico) entendemos las formas de empleo del diálogo para articular y en lo posible resolver los dilemas causados por las ciencias y las tecnologías(3, p.20)”.

De esta definición resalto los siguientes aspectos:

1) Se trata de una disciplina dialógica, por lo tanto, secular y procedimental.

2) En bioética no hay problemas strictus sensus sino más bien dilemas o, mejor, poliemas. Esto significa que no existe una única solución y también que cualquier solución implica un nuevo problema. De allí la importancia de respetar la diferencia de opiniones fundamentadas.
3) De lo anterior se deduce que no siempre (o casi nunca) es posible dar respuestas categóricas. Muchas veces debemos contentarnos con la elucidación del conflicto. Por ello, no puede haber expertos.

Si optamos por los intereses emancipatorios, por la realización de la comunidad ideal de diálogo y aceptamos la anterior definición de bioética, es claro que esta disciplina ha de pertenecer al nivel postconvencional de la conciencia moral, es decir, ha de ir más allá de las normas jurídicas, religiosas o sociales. En este sentido no puede ni debe funcionar como institución. De permanecer en el nivel convencional, como creo corre el riesgo de estar en base a las características que he expuesto, negará el pluralismo y pseudolegitimará lo que es de hecho.

Defender el pluralismo no significa caer en el relativismo absoluto, sino aprobar las opciones defendibles argumentativamente y que no se opongan a los intereses del otro. Una opción es correcta cuando puede ser aceptada por todos los afectados y surge del diálogo en condiciones de libertad y de simetría, es decir, cuando es el resultado de la racionalidad comunicativa y no de la manipulación, la coacción o la negociación estratégica. Por cierto que cada quien llevará a la mesa de discusión sus propias convicciones e intentará que sean compartidas por los otros; todo esto es legítimo en tanto el camino sea la invitación a través de la persuasión, en el marco del respeto por las diferencias.

Es aquí donde tiene lugar la tolerancia o, más bien, preferiría hablar de solidaridad. Como se sabe, el principio de tolerancia surge en el siglo XVII, como una manera práctica de poner fin a siglo y medio de guerras entre católicos y protestantes. En su origen no implicaba, entonces, un reconocimiento positivo del derecho que el otro tiene a sus propias creencias o valores. Se trataba más bien de un compromiso táctico y negativo de no beligerancia. Cuando se acepta 
Algunas observaciones sobre el estado actual de la Bioética en Argentina - D. Outomuro

que las creencias del otro deben respetarse porque ellas son en sí mismas respetables, la tolerancia abre paso a la libertad de conciencia, tarea que ha tenido como pioneros a Espinoza y Locke(12). La bioética debería avanzar por este camino y conducirnos a la solidaridad: tolerancia, libertad de conciencia, solidaridad.

Tolerar es aceptar pasivamente y con resignación los intereses del otro, porque no queda otro remedio. Respetar la libertad de conciencia es reconocer el derecho a la diferencia pero, en mi opinión, también negativamente. Por el contrario, la solidaridad conlleva la actitud activa y positiva de colaborar con los proyectos del prójimo, por mucho que ellos difieran de nuestras propias convicciones.
Esta comunidad ideal de comunicación sólo puede realizarse cuando se respetan, glosando a Adela Cortina, aquellos mínimos morales esenciales para la convivencia democrática: el reconocimiento del otro como persona así como de sus necesidades, proyecto e intereses vitales; la disposición a razonar y a alcanzar acuerdos mediante argumentos; el compromiso en la mejora material y cultural tendiente a alcanzar el máximo de simetría y, como se ha dicho, el reemplazo de la tolerancia por el compromiso activo, es decir, por la solidaridad y la fraternidad. En síntesis, de lo que se trata es de aprender de una buena vez que respetar no es sinónimo de compartir y que el respeto por el otro es condición sine qua non de la vida democrática.

\section{Referencias}

1. Lolas Stepke F. El discurso bioético y la acción social. En: Actas de la Primera Jornada de Bioética de la Facultad de Medicina de la Universidad de Buenos Aires. Buenos Aires: Facultad de Medicina; 2002: 77-8.

2. Lolas Stepke F. Oficio de anotar. Santiago de Chile: Editorial Universitaria; 2000: 175.

3. Lolas Stepke F. Temas de bioética. Santiago de Chile: Editorial Universitaria; 2002: 15-25.

4. Lolas Stepke F. Bioética y Antropología Médica. Santiago de Chile: Mediterráneo; 2000: 59-60.

5. Lischetti M. Antropología. Buenos Aires: EUDEBA; 1985: 24.

6. Cortina A. Ética de la empresa. Madrid: Trotta; 2000: 50.

7. Gracia Guillén D. Fundamentación y enseñanza de la bioética. Bogotá: El Búho; 2000: 63.

8. Engelhardt HT. Los fundamentos de la bioética. Barcelona: Paidós; 1995: 27.

9. Maliandi R. Ética: conceptos y problemas. Buenos Aires: Biblos; 1991: 50.

10. Camps V. Una calidad de vida. Barcelona: Ares y Mares; 2001: 214.

11. Ferrater Mora J. Diccionario de Filosofía. Barcelona: Ariel; 1994: 1542.

12. Gracia Guillén D. Bioética Clínica. Bogotá: El Búho; 2001: 125-126. 